\title{
Antibody-Mediated Blockade for Galectin-3 Binding Protein in Tumor Secretome Abrogates PDAC Metastasis
}

\section{Yeon-Sook Choi}

University of Ulsan

Myung Ji kim

University of Ulsan

Eun A Choi

University of Ulsan

Sinae Kim

University of Ulsan

Eun Ji Lee

University of Ulsan

Hyun Ji Kim

University of Ulsan

Jae Yun Jung

University of Ulsan

Hyori Kim

Asan Medical Center

Kyung Kon Kim

University of Ulsan

Jin Young Kim

KBSI

\section{Seung Mo Hong}

Asan Medical Center

\section{Song Cheol Kim}

Asan Medical Center

Suhwan Chang ( $\square$ suhwan.chang@amc.seoul.kr)

University of Ulsan College of Medicine https://orcid.org/0000-0002-0282-0120

\section{Research}

Keywords: Galectin-3 Binding Protein, Pancreatic Ductal Adenocarcinoma, Tumor Interstitial Fluids, Metastasis, EGFR, Blocking Antibody 
Posted Date: July 9th, 2021

DOI: https://doi.org/10.21203/rs.3.rs-676413/v1

License: (c) (i) This work is licensed under a Creative Commons Attribution 4.0 International License. Read Full License 


\section{Abstract \\ Background}

One of the major challenges in pancreatic ductal adenocarcinoma (PDAC) management is a local or distant metastasis and limited targeted therapeutics to prevent the process. We aimed to identify a druggable target by screening abnormally secreted protein from PDAC and explore its therapeutic intervention.

\section{Methods}

A LC-MS/MS-based proteomics was carried out for TIF (Tumor Interstitial Fluids) obtained from patient derived xenograft (PDX) models of PDAC. To develop a blocking antibody for selected target protein, antibody phage-display technology was used.

\section{Results}

The proteomic screening of PDAC secretome identified Galectin-3 binding protein (Gal-3BP hereafter) as a top candidate. The Gal-3BP is highly expressed and secreted in PDAC tumors and primary cells.

Subsequent functional tests by stable knockdown revealed the Gal-3BP is required for PDAC cell proliferation, migration and invasion. In addition, the depletion of Gal-3BP significantly abrogated in vivo tumor formation and metastasis of pancreatic cancer cells. Mechanistically, we found Gal-3BP enhances the galectin-3 mediated EGFR signaling, leading to the activation of $\mathrm{CMyc}$ and its target genes related to EMT. To examine the clinical usability of these findings, we screened a Gal-3BP-immunized chicken antibody library using phage display technique. The two isolated blocking antibody clones against Gal3BP profoundly inhibited the metastasis of PDAC cells in vivo.

\section{Conclusions}

Altogether, our data demonstrates the Gal-3BP is an important therapeutic target in PDAC and proposed its blockade by antibody as a novel, therapeutic option for the inhibition of PDAC metastasis.

\section{Background}

One of the challenges faced in PDAC management is the absence of targeted therapeutics[1,2]. Thus, finding a druggable target is critical. In addition to the mutant K-Ras, which has been identified as a dominant driver and therapeutic target in recent studies[3, 4], multiple targets including EGFR, PI3K, Raf, MEK and TGF- $\beta$ are being investigated[5, 6]. However, the clinical application of these target proteins is still under investigation and the strategies used for targeting the proteins do not take into consideration the genetic and intratumoral heterogeneity of PDAC[1, 7]. 
The tumor secretome $[8,9]$ is an important source of therapeutic or diagnostic targets. As tumor-derived proteins or bioactive molecules are often diluted in the blood, the detection of a locally secreted protein is an attractive alternative method for identifying novel target proteins[10]. In practice, analyses of the interstitial fluid obtained from tumor[11] have revealed the enrichment of cytokines in breast cancer [12], S100A in cholangiocarcinoma[13] and Fascin in head and neck cancer[14]. Considering the presence of a stromal-rich microenvironment[15] and intricate communication between PDAC and stellate cells[2, 16], an investigation of tumor interstitial fluid (TIF) and antifibrotic therapy in pancreatic cancer seems promising[17]. Indeed, a recent study demonstrated that the metabolite profile of PDAC-TIF is distinct from that of the plasma[18]. Despite the potential advantages associated with analysing the TIF, few reports exist regarding the proteomic analysis of PDAC-TIF. This might be due to the difficulty in obtaining fresh PDAC tissue for TIF isolation. Moreover, the high variability in the proteomic profiles of individual tumours makes it necessary to investigate large number of specimens for achieving a statistical significance. To circumvent these limitations, we had developed a patient-derived xenograft (PDX) model of PDAC[19] and compared the TIF proteome data with those of breast cancer PDX[20], thereby ensuring PDAC-specific or PDAC-enriched target identification.

Galectin-3 binding protein (Gal-3BP) is a highly glycosylated protein that has been identified in multiple screening studies investigating tumor-secretory proteins in melanoma[21], lung carcinoma[22], and breast cancer[23]. Apart from Galectin-3, Gal-3BP can also interact with Galectin-1, $\beta 1$-integrins, and ECM proteins, including collagen, fibronectin, and laminin[24]. In cancer, Gal-3BP is mainly involved in cellmatrix or cell-cell interactions and affects metastasis or tumor cell-stromal cell communication[25, 26]. Despite extensive research, the role of Gal-3BP in pancreatic cancer remains largely unknown, probably because Gal3-BP is expressed at low levels in the pancreas under normal conditions (from public data; available at https://www.proteinatlas.org/ ENSG00000108679-LGALS3BP/tissue). In this study, we identified high levels of Gal-3BP in PDAC-TIF. Furthermore, the results of this study reveal a novel function of Gal-3BP in PDAC and indicate that antibody-mediated Gal-3BP blockade might serve as a promising therapeutic strategy against PDAC.

\section{Methods}

\section{Ethical guidelines}

Human PDAC specimens were obtained with permission from the institutional review board (IRB) of the Asan Medical Center (No. S2013-0744-0009). Protocols for animal experimentation were reviewed and approved by the Institutional Animal Care and Use Committees (IACUC) of Asan Institute for Life Sciences (AILS, Project Number: 2015-12-164). All mice were maintained in the specific pathogen-free (SPF) facility of the Laboratory of Animal Research at the Asan Institute for Life Sciences (Seoul, South Korea).

\section{Cell culture and transfection}

Human pancreatic cancer cell lines were maintained in DMEM supplemented with 10\% FBS and 1\% penicillin/streptomycin. Primary pancreatic cancer cells were cultured in RPMI supplemented with 5\% 
FBS, $1 \%$ penicillin/streptomycin, $20 \mathrm{ng} / \mathrm{ml} \mathrm{EGF,} 4 \mu \mathrm{g} / \mathrm{ml}$ hydrocortisone, and $4 \mu \mathrm{g} / \mathrm{ml}$ transferrin. HPDE cells were cultured in keratinocyte serum-free medium supplemented with EGF and bovine pituitary extract (Invitrogen). All cells were cultured at $37^{\circ} \mathrm{C}$ in an atmosphere containing $5 \% \mathrm{CO}_{2}$. Cells were transfected with control siRNA or LGALS3BP siRNA using Lipofectamine 2000 (Invitrogen). LGALS3BP siRNA was designed by Genolution Inc., and had the following sequence: 5'-

CGCACCAUUGCCUACGAAAUU-3'.

\section{Primary culture}

Primary cancer cells were isolated from tumours derived from patient-derived xenograft models. Fresh tumor tissue was minced into 1-2 mm pieces using sterile scissors, scalpel, and forceps. For tissue digestion, the tissue pieces were placed in a $15 \mathrm{ml}$ conical tube containing 3-5 ml RPMI 1640 medium (PAN, DEU) supplemented with 5\% FBS (PAN, AUS), 1\% penicillin/streptomycin (Hyclone, USA), $20 \mu \mathrm{g} / \mathrm{ml}$ of collagenase Type $\otimes$ (Sigma Aldrich, USA), and $840 \mathrm{ng} / \mathrm{ml}$ Fungizone (Gibco, USA), and incubated on a shaking incubator at $37^{\circ} \mathrm{C}$ for $2 \mathrm{~h}$. Following incubation, the digested tissue pieces were washed with RPMI 1640 medium and centrifuged at $800 \mathrm{rpm}$ for $3 \mathrm{~min}(\mathrm{x} 3)$. The tissues were placed in a collagencoated T25 flask, and cultured using RPMI 1640 medium supplemented with 5\% FBS, 1\% penicillin/streptomycin, $20 \mathrm{ng} / \mathrm{ml}$ hEGF (Gibco, USA), $4 \mu \mathrm{g} / \mathrm{ml}$ hydrocortisone (Sigma Aldrich, USA), 4 $\mu \mathrm{g} / \mathrm{ml}$ transferrin (Sigma Aldrich, USA), and $840 \mathrm{ng} / \mathrm{ml}$ Fungizone at $37^{\circ} \mathrm{C}$ in an atmosphere containing $5 \% \mathrm{CO}_{2}$. After 2-4 days of incubation, cells started to attach to the collagen-coated surface of the T25 flask.

\section{Antibodies and reagents}

Cells were lysed in RIPA buffer containing protease and phosphatase inhibitors. Lysates were centrifuged at $14,000 \mathrm{rpm}$ for $15 \mathrm{~min}$, and the supernatant was collected. Subsequently, the proteins were separated via SDS-polyacrylamide gel electrophoresis. Immunoblotting was performed using antibodies against LGALS3BP (R\&D systems), P-EGFR (Cell Signaling), EGFR (Cell Signaling), CA19-9 (Abcam), and $\beta$-actin (Santa Cruz Biotechnology).

\section{shRNA-mediated knockdown of Gal-3BP}

Plasmids targeting containing shRNA against human and mouse LGALS3BP were purchased from Sigma Aldrich; human LGALS3BP (\#1 TRCN0000029418; \#2 TRCN0000372778; \#3 TRCN0000029417; \#4 TRCN0000372838; \#5 TRCN0000029414), and mouse LGALS3BP (\#1 TRCN0000325878; \#2 TRCN0000066333; \#3 TRCN0000066334; \#4 TRCN0000066336; \#5 TRCN0000066335). In order to generate recombinant lentiviruses, HEK293T cells were co-transfected with a lentiviral expression vector and lentiviral packaging vectors (VSVG and PAX2), using lipofectamine 3000 (Invitrogen, Camarillo, CA). Subsequently, the supernatants were collected twice at intervals of 1 day. For transduction of 110621 or PKCY cells, lentiviruses were included in the culture medium for 2 days. Finally, to select cells with a stable knockdown, a selection pressure was applied by using puromycin $(1 \mu \mathrm{g} / \mathrm{ml})$ or puromycin $(2$ $\mu \mathrm{g} / \mathrm{ml})$. 


\section{Migration, invasion, and proliferation assays}

The migration and invasion abilities of the cells were assayed by using Transwell chambers (Corning Costar) and Matrigel-coated chambers containing $6.5 \mathrm{~mm}$ diameter polycarbonate filters ( $8 \mu \mathrm{m}$ pore size), respectively. The cells were trypsinized and suspended at a final density of $1 \times 10^{6} \mathrm{cell} / \mathrm{s} / \mathrm{ml}$ in serum-free medium. Subsequently, $100 \mu \mathrm{l}$ of the cell suspension was loaded into each of the upper wells, and culture medium supplemented with serum was added to the plate as a chemoattractant. The chamber was incubated at $37^{\circ} \mathrm{C}$ for $24 \mathrm{~h}$. Following this, the cells were fixed and stained with haematoxylin and eosin. Non-migrated cells in the upper chamber were removed using a cotton swab. The number of migrated and invaded cells was quantified by manual counting under an optical microscope (x200). Cell viability was evaluated using Ezcytox according to the manufacturer's protocol. Cells were seeded at a density of $2 \times 10^{3}$ cells $/ 100 \mu$ in each well of a 96-well plate and incubated at $37^{\circ} \mathrm{C}$ for $72 \mathrm{~h}$. The absorbance of the wells was measured at $450 \mathrm{~nm}$ using a Molecular Devices microplate reader, with a reference wavelength of $650 \mathrm{~nm}$.

\section{Immunohistochemical analysis}

Fresh specimens were immersed in 10\% Formalin for 4 days and subsequently embedded in paraffin. Paraffin sections (4- $\mu \mathrm{m}$ thick) were de-paraffinized using xylene and rehydrated by treatment with graded alcohols. Endogenous peroxidase activity was blocked using 3\% hydrogen peroxide prepared in methanol for 20 min. Antigen retrieval was performed via heat treatment in Tris-EDTA buffer (Abcam) for 20 min, followed by incubation with $3 \%$ normal goat serum for 20 min to block nonspecific binding. After blocking, the sections were incubated with Ki67 antibody (Abcam, 1:50) diluted in 1\% normal goat serum at $4{ }^{\circ} \mathrm{C}$ overnight. Sections were rinsed in PBS and incubated with HRP-conjugated secondary antibody (1:200) at room temperature for $1 \mathrm{~h}$. Finally, the sections were developed using diaminobenzidine (DAB) (Thermo Scientific) and counterstained with haematoxylin. The samples were mounted with coverslips using Permount (Fisher Scientific) and the sections were observed under a light microscope. Analysis was performed using Image $\mathrm{J}$.

\section{Immunofluorescence (IF) staining of PDX tissues}

PDX samples for IF staining were embedded into OCT and store at $-80^{\circ} \mathrm{C}$ deep freezer until ready for sectioning. The samples were cut into $5-\mu \mathrm{m}$ sections on a cryostat. IF staining was performed according to the manufacturer's instructions (R\&D system, Minneapolis, USA). In brief, Tissues were incubated overnight at $4^{\circ} \mathrm{C}$ with primary antibodies: Galectin-3BP ( $1 \mathrm{ug} / \mathrm{ml}, \mathrm{R} \& \mathrm{D}$ systems, Minneapolis, MN, USA) and Galectin-3BP \#84 \& 67 (1ug/ml, Custom Mouse Monoclonal Antibodies, Asan Medical Center Core). Tissue was then stained with 1:1000-diluted secondary antibodies; donkey anti-goat Alexa Fluor 488 (Invitrogen, Thermo Fisher Scientific, Waltham, MA, USA) and goat anti-mouse Alexa Fluor 488 (Invitrogen) Images were captured using a LMS710 confocal microscope (ZEISS, Jena, Germany), analyzed using Image ZEN black edition (ZEISS).

In vivo tumor formation and imaging 
Cells (110621 cell line) were resuspended in $100 \mu$ l PBS at a density of $2 \times 10^{6}$ and injected into the dorsal flank of 6-8-week-old male BALB/c nude mice. Tumor growth was monitored and tumor volume was measured using calipers. Tumor size $\left(\mathrm{mm}^{3}\right)=\mathrm{L}$ (Length) $\times \mathrm{W}^{2}$ (width)/2. Subcutaneous tumours were excised and weighed. Subsequently, tumor tissues were fixed in formalin, embedded in paraffın, and then stained with H\&E. Immunohistochemistry was performed to check the expression of Ki-67, which is a marker of proliferating cells, and the number of positively-stained cells was calculated by counting the number of immune-positive cells in five selected fields under a microscope.

\section{Tissue microarray (TMA) analysis}

Pancreatic ductal adenocarcinoma (PDAC) for TMA were collected from Asan Medical center Tissue cores (Seoul, South Korea). Tissue blocks and their matching hematoxylin-and eosin-stained slides were retrieved and confirmed by pathologist to identify representative tumor regions. PDAC $(n=153)$ or matched normal pancreas $(n=21)$ were sampled from representative areas using a 2.0-mm punch. For Galetin-3BP IHC staining, paraffin embedded samples were cut 4- $\mu \mathrm{m}$ sections and incubated with primary antibodies against Galectin-3BP (1:100, Solarbio Life Sciences, Beijing, China) and Galectin-3BP \#84 \& 67 (10 ug/ml, Custom Mouse Monoclonal Antibodies, Asan Medical Center Core) overnight. Images were taken using a digital camera DP27 (Olympus, Shinjuku, Japan) coupled to an Olympus BX53 Upright Microscope (Olympus). Images were analyzed by Olympus CellSens Standard software. Based on the percentages of Galectin-3BP-positive cells, the data were subdivided into four categories as follows: (0) 10\%; (1) 11-30\%; (2) 30-50\%; and (3) > 50\% positive cells. Semiquantative intensity was scored as 0 (negative), 1 (weak), 2 (moderate) and 3 (strong) (Fig. 1G).

\section{TIF isolation and proteomic analysis}

Tumor tissues weighing $0.25 \mathrm{~g}$ were cut into small pieces $\left(1-3 \mathrm{~mm}^{3}\right)$ and carefully washed in $3 \mathrm{ml}$ of phosphate-buffered saline (PBS). Tumor samples were subsequently transferred to $1.5 \mathrm{ml}$ tubes and incubated at $37^{\circ} \mathrm{C}$ for $1 \mathrm{~h}$ in $1 \mathrm{ml}$ PBS in a humidified $\mathrm{CO}_{2}$ incubator. The samples were then centrifuged and the supernatant was collected. The LC-MS/MS analysis of the tumor secretome was described previously[27].

\section{Phage display for the Gal-3BP antibody screening}

Three White Leghorn chickens were immunized and boosted thrice with the recombinant Gal-3BP protein produced in-house. Chickens were euthanized a week after receiving the third booster dose, and their spleens as well as bone marrows were harvested for total RNA isolation using TRIzol Reagent (Thermo Fisher Scientific). Complementary DNA (cDNA) was synthesized using SuperScript® IV First-Strand Synthesis System (Thermo Fisher Scientific), according to the manufacturer's protocol. Using cDNA as a template, the genes encoding the variable regions of heavy and light chains were amplified and used for the construction of a chicken scFv-displayed phage library, as previously described [28]. The chicken scFv-displayed phage libraries were subjected to four rounds of bio-panning against Gal-3BP protein, in 
accordance with the existing protocols [29]. The nucleotide sequences of the reactive scFv clones were determined by Sanger sequencing (Cosmogenetech, Seoul, Korea).

\section{Antibody treatment of mouse model of PDAC with lung metastasis}

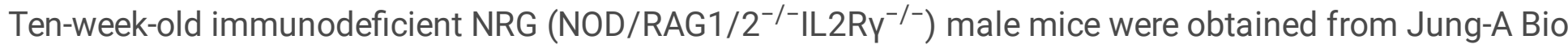
Laboratories (Osong, South Korea). For the lung metastasis model, a primary pancreatic cancer cell line (110621) with stable luciferase expression was used. The primary PDAC cells with luciferase expression were generated by transfecting with retroviral vector (pMXs-IRES-Puro Retroviral Vector, RTV-014) obtained from a packaging cell line (Platinum-A Retroviral Packaging Cell Line, Amphotropic, RV-102). The cells were resuspended at a density of $2 \times 10^{5}$ cells/100 $\mu$ in Matrigel (Corning ${ }^{\circledR}$ Matrigel $\circledast$ Matrix from Corning Life Sciences) and injected into the tail vein. One week post-surgery, the luciferase signal in the tumor was monitored using the IVIS Spectrum In Vivo Imaging System (Perkin-Elmer). Antibody treatment was performed in the following three groups: IgG-treated control $(n=4)$, \#67 antibody-clonetreated $(n=6), \# 84$ antibody-clone-treated $(n=6)$. The antibodies were intravenously injected $(200 \mu l ; 1$ $\mathrm{mg} / \mathrm{ml}$ ), once a week. After four injections, the mice were euthanized, and tumours were analysed.

\section{Statistics}

All data are presented as mean \pm standard error. The comparisons between two groups were performed using the Student's $t$-test and comparisons among multiple groups were performed using ANOVA. $P$ values $<0.05,<0.01$, and $<0.001$ were denoted as $*$, $*$, and $\star \star \star$ respectively, to indicate significance.

\section{Results}

Identification of Gal-3BP as a secreted protein in the TIF via proteomic analysis of the PDAC PDX model

To identify a cancer-specific druggable protein target in the pancreas, we analysed three TIFs obtained from the PDX model of PDAC, along with three TIFs from breast cancer PDX models. In the initial analysis using LC-MS/MS, 1413 proteins for PDAC and 1822 proteins for breast PDX were detected (Fig. 1A). Among them, 87 proteins were expressed at higher levels in PDAC (Cut-off 2.5-fold, Supplementary Table 1 for raw data) compared to those in the breast. Based on the up-regulated fold and literature search for subcellular localization, we selected two secreted proteins i.e., LGALS3BP and Progranulin (PGRN). The increased expression of Gal-3BP and PGRN in PDAC TIFs was confirmed (Fig. 1B). Moreover, high levels of these proteins were observed in the culture media of PDAC cells, indicating active secretion (Fig. 1C). Consistent with their enhanced secretion, the two candidate targets showed elevated expression at the protein (Fig. 1D) and mRNA levels (Fig. 1E). Further, Gal-3BP-but not PGRN-was detected in the plasma of the PDX model (Fig. 1F); this suggested that Gal-3BP can be detected in liquid biopsy samples. Therefore, we focused on Gal-3BP for further study. IHC analysis of Tissue Microarray $($ TMA) containing PDAC $(n=153)$ and matched normal $(n=21)$ validated our finding 
(Fig. 1G, Supplementary Fig. 1 for raw data), indicating the Gal-3BP is significantly over-expressed in PDAC compared to normal tissue (Fig. 1H)

Stable knockdown of Gal-3BP significantly reduces the growth and tumorigenic potential of PDAC cells

Upregulation of Galectin-1 and Galectin-3 has been observed in cancer[30, 31]. Considering the primary binding partners of Gal-3BP are Galectin-1 and Galectin-3, we first investigated the function of Gal-3BP with respect to cell proliferation by knocking it down in primary PDAC cells. Figure 2A depicts the expression of Gal-3BP at the mRNA (graph) and protein levels (upper panel) after stable knockdown. In three independent stable cell lines expressing shRNA against Gal-3BP, significantly attenuated cancer cell proliferation was observed (Fig. 2B). Importantly, when two of the stable cell lines were transplanted into nude mice, the tumor formation rate was dramatically reduced (Fig. 3C), compared to that in mice transplanted with wildtype cells (2 tumours versus 10). Moreover, the two tumours formed upon injecting the 3BP_Sh2 cell line showed slower growth (Fig. 3D) and low weight (Fig. 3E). Further analysis confirmed the reduced expression of Gal-3BP (Fig. 2G) and Ki-67 in the tumor (Fig. 2F). These data suggest that Gal-3BP is required for PDAC cell growth both in vitro and in vivo.

Gal-3BP knockdown significantly reduces the adhesion and migration of PDAC cells

A previous study reported that the silencing of Galectin-3 results in suppressed pancreatic cancer cell migration[32]. However, the effect of Gal-3BP with respect to PDAC cell mobility remains unknown. Therefore, we investigated if Gal-3BP knockdown can alter the ability of PDAC cells to adhere and migrate. We observed that Gal-3BP siRNA transfection (Fig. 3A) markedly suppressed the adhesion (Fig. 3B), migration (Fig. 3C), and invasion ability of primary PDAC cells (Fig. 3D). Moreover, transfection of primary PDAC cells with Gal-3BP siRNA resulted in reduced expression of EMT markers, such as Zeb1, Claudin-1, and Snail (Fig. 3E, Supplementary Fig. 2 for PDC data). Conversely, Gal-3BP overexpression in primary PDAC cells resulted in the upregulation of N-cadherin, Snail, and Zeb1 (Fig. 3F).

Stable knockdown of Gal-3BP significantly attenuates PDAC cell metastasis in a mouse model

Based on the in vitro data shown in Fig. 3, we examined the role of Gal-3BP in tumor metastasis in vivo. Towards this, we used murine PDAC cells (PKCY; a kind gift from Dr. Sung Jin Kim) isolated from LSLKras G12D; Trp53 R172H; Pdx1-Cre spontaneous model[33]. Gal3-BP knockdown in PKCY cells (Fig. 4A) also resulted in reduced proliferation (Fig. 4B), migration (Fig. 4C), and EMT marker expression (Fig. 4D), consistent with the human PDAC data presented above. Using tail-vein injection, we assessed the ability of PKCY cells to form tumors in the lungs (Fig. 4E and Supplementary Fig. 3). Lung weights (Fig. 4F) and nodule counts (Fig. 4G) indicated that Gal-3BP knockdown significantly suppressed PDAC cell metastasis into lungs.

Gal-3BP interacts with and enhances EGFR signalling in PDAC cells

Galectin-3 activates EGFR signalling in several cancers[34-36]. As EGFR is frequently up-regulated and associated with poorer prognosis in PDAC[37], we examined whether EGFR activation in PDAC is affected 
by the up-regulation of Gal-3BP, in combination with Galectin-3. Indeed, p-EGFR level is reduced upon Gal3BP knockdown in primary PDAC cells (Fig. 5A, left). Conversely, secreted Gal-3BP (Supplementary Fig. 4A) treatment on Panc1 cells markedly increased p-EGFR levels (Fig. 5A, right). In addition, we observed reduced EGFR expression at the mRNA level (Fig. 5B) by stable Gal-3BP knockdown. In the presence of EGF, the time-dependent activation of EGFR was dramatically abolished in cells with stable Gal-3BP knockdown (Fig. 5C), indicating that Gal-3BP is a positive regulator of EGFR activation. This finding is further supported by the combinatorial treatment of two primary PDAC cell lines with recombinant Gal-3BP and EGF, showing enhanced p-EGFR level (Fig. 5D).

Hence, we examined how Gal3-BP affects Galectin-3-mediated EGFR activation in PDAC cells. Interestingly, both combinations of EGF(E) plus Galectin-3(G3) and EGF plus Gal-3BP(3BP) could enhance EGFR phosphorylation (Fig. 5E, Supplementary Fig. 4B). Moreover, combinatorial treatment with Galectin-3, EGF, and Gal-3BP markedly enhanced p-EGFR levels (Fig. 5E, last lane). Further, the treatment of EGF on PDAC cells resulted in increased Gal-3BP levels (Fig. 5F) whereas the treatment with the EGFR inhibitor dramatically inhibited it (Fig. 5G). These data suggest that a positive feedback-loop exists in the Gal3-BP-EGFR signalling. The co-immunoprecipitation analysis indicated the Gal-3BP associated with EGFR (Supplementary Fig. 4C). We next examined the effect of Galectin-3 knockdown on Gal-3BPmediated EGFR activation and found Galectin-3 knockdown partially inhibited p-EGFR level, indicating that Galectin-3 is required-at least in part-for the Gal-3BP-mediated EGFR activation (Fig. $5 \mathrm{H}$; see discussion).

Gal-3BP positively regulates cMyc via EGFR activation in PDAC cells

Our data in Fig. 3 indicated that Gal-3BP is required for cellular attachment, migration, and invasion. Based on these results, we sought to identify a functional mediator that-can be activated in response to EGFR signalling-regulates such cellular events. A previous study showed that cMyc is an effector of EGFR signalling in murine pancreatic ductal epithelial cells[38]. Moreover, a recent report demonstrated that cMyc alone can result in the transformation of PanIN cells into PDAC cells[39]. Therefore, we investigated whether Gal-3BP regulates cMyc expression via EGFR activation. A stable knockdown of Gal3BP (Fig. 6A, top panel) resulted in the downregulation of cMyc at the mRNA level (Fig. 6A, bottom). This result was further validated in another primary PDAC cell clone with transient knockdown of Gal-3BP (Fig. 6B). Conversely, the Gal-3BP alone or a combination of Gal-3BP and EGF upregulated cMyc (Fig. 6C). Consistently, the EGFR inhibitor effectively suppressed cMyc upregulation upon the Gal-3BP treatment (Fig. 6D), indicating that EGFR activation is necessary for the Gal-3BP-mediated cMyc activation. In addition, two tumours with stable knockdown of Gal-3BP (see Fig. 2C and 2D) also showed markedly reduced cMyc expression (Fig. 6E). Consequently, a reduced expression of several cMyc target genes were observed (Supplementary Fig. 4D). These data collectively indicate that Gal-3BP enhances EGFR-Myc signalling in PDAC cells. Importantly, the reduced proliferation in response to Gal3-BP knockdown (shown in Fig. 2B) is partially recovered upon the exogenous expression of cMyc (Fig. 6F), confirming that Gal-3BP-induced PDAC cell proliferation is mediated by cMyc. 
Treatment with Gal-3BP antibodies inhibits EGFR-Myc signalling and metastasis in PDAC cells

Although Gal-3BP knockdown using shRNA significantly attenuated tumor formation as well as cell migration, the shRNA approach has limitations with respect to clinical application. To develop a therapeutic agent targeting Gal-3BP, we employed an antibody phage display technique [40] to screen specific antibodies against Gal3-BP (Fig. 7A). Initial hit antibodies- obtained by screening a Gal-3BPimmunized chicken antibody library-exhibited high affinity to recombinant Gal-3BP protein in vitro, as verified by ELISA. Among five candidate antibodies, we selected clones \#67 and \#84 owing to their inhibitory effect on cell migration (Fig. 7B and 7C, Supplementary Fig. 5A), although they did not significantly interfere with cell proliferation (Supplementary Fig. 5B). Gal-3BP binding ability of clones \#67 and 84 was confirmed by immunoprecipitation (Fig. 7D). Consistent with the results of shRNA, the treatment of these two antibodies on primary PDAC cell lines showed a decreased EGFR activation and cMyc expression, although it was not as effective as siRNA-mediated gene silencing (see discussion, Supplementary Fig. 5C-5F).

Importantly, we also observed the \#67 and \#84 antibody clones detect Gal-3BP protein in orthotopic PDAC tumor tissues in both of immunofluorescence (Supplementary Fig. 6A, 6B) and immunohistochemical staining (Supplementary Fig. 6C). Based on this, we further examined the efficacy of these two Gal-3BP antibodies in metastatic tumor model. Human primary PDAC cells with stable luciferase expression (Supplementary Fig. 7A) were transplanted into mouse via tail vein, and lung tumor growth was monitored by IVIS imaging in conjunction with antibody treatment. Supplementary Fig. 7B depicts the representative IVIS images for three groups (IgG, \#67, and \#84 antibody-treated). After 2 weeks of treatment, we observed an overall reduction in the ROI values in the Gal-3BP-antibody-treated groups, although it was not significant owing to the high intra-group variation (Supplementary Fig. 7C). The H\&E staining of dissected lung tissue revealed nodules generated by metastasized PDAC cells, marked by the grids in Fig. 7E. We found that the number of nodules (Fig. 7F) as well as the metastatic index (measured from the area of cancer cells in the lung, Fig. 7G) were significantly reduced after treatment with the two Gal-3BP antibody clones. These data collectively demonstrate that the blocking of Gal-3BP using specific antibodies is a good strategy to attenuate PDAC metastasis (see graphical abstract).

\section{Discussion}

A major obstacle in the identification of a drug target or tumor biomarker using the patient samples is the variability across donors, including genetic diversity, lifestyle, disease state, and therapeutic history of each patient[41]. To overcome this, a large number of specimens as well as precise statistical analysis is needed, but this not always possible in pancreatic cancer research[42]. In this respect, the patient-derived xenograft (PDX) model serves as an effective preclinical model, wherein most of the host variables are controllable and an ideal control (ungrafted littermates) can be easily obtained[43]. Therefore, despite the known limitations, such as a compromised immune environment[44], the PDX model enables us to design a simple (with a small number of mice), rapid screening strategy for the identification of protein 
biomarkers or therapeutic targets. Further, a dilution effect as well as the intrinsic low-level expression of the tumor-originated secreted protein make the identification of blood biomarkers difficult[45]. To circumvent this limitation, we introduced the analysis of tumor interstitial fluid (TIF) and managed to improve the detection of the candidate marker proteins.

The interaction of EGF with EGFR and its activation is well characterized[46]. However, despite its critical role in tumorigenesis, not much is known about EGFR-binding proteins (other than EGFR). The STRING database[47] shows approximately 10 protein interactions, but most of them are adaptors or kinases that transmit the activation signal in the cytoplasmic domain (Supplementary Fig. 7D). In this respect, characterization of EGFR activating protein contributes to the understanding of EGFR activation as well as in designing a therapeutic target. Galectin-3 has been shown to activate EGFR in pancreatic cancer[36] and other cancer types[48, 49]. In parallel with the recent progress on the Galectin-3 antagonist[50, 51], we demonstrate here that anti-Gal-3BP antibody is an alternative for effectively blocking the activation of EGFR in PDAC.

Although we have successfully developed antibodies against Gal-3BP and demonstrated their antitumor effect in a mouse model, several points need to be considered in order to translate this into a therapeutic agent for cancer patients. Firstly, recent reports indicated a multifunctional role of Gal-3BP, not only in cancer but also in innate immunity function[52]. In the report, Gal-3BP is induced in response to viral and bacterial infection and regulates cytokine production/secretion, viral assembly, as well as LPS (lipopolysaccharide) response[53]. Therefore, selective delivery method to tumor site or an appropriate dosage of anti-Gal-3BP antibody should be predetermined in order to prevent adverse anti-immune function.

Despite these limitations, we propose the Gal-3BP antibody as a promising therapeutic agent, since it effectively attenuated the metastasis of PDAC cells in our mouse model. One of the major challenges in pancreatic cancer is its highly metastatic nature which restricts the resectable tumor to $15-25 \%$ upon diagnosis[54]. Therefore, in addition to early detection, identifying a therapeutic option to prevent or suppress metastasis is critical for the management of pancreatic cancer. Several potential antimetastatic agents, including matrix metalloproteinase inhibitor[55], JG243 (HIF-1a inhibitor[56]), JQ1 (vasculogenic mimicry inhibitor[57]), AZD6244 (MEK inhibitor) with BMS833923 (Hh inhibitor)[58], and Metavert (GSK3B and HDAC inhibitor[59]) have been identified. Future studies should focus on combinatorial therapy with Gal-3BP antibody and these anti-metastatic agents as well as a promising combination with immunotherapy[60,61], which will broaden the options available for enhancing the survival of PDAC patients.

\section{Conclusions}

PDAC metastasis is a major cause for the poor prognosis of PDAC patients and developing targeted therapeutic is critical to overcome it. Our results presented here revealed a novel, promising target for PDAC metastasis and showed the antibody-mediated blockade as a therapeutic option. 


\section{Abbreviations}

EGFR; Epidermal Growth Factor Receptor

EMT; Epithelial Mesenchymal Transition

Gal3-BP; Galectin-3 Binding Protein

LC-MS; Liquid Chromatography-Mass Spectrometry

PDAC; Pancreatic Ductal Adeno Carcinoma

PDX; Patient Derived Xenograft

PGRN; Progranulin

ROI; Region Of Interest

TIF; Tumor Interstitial Fluids

\section{Declarations}

Ethics approval and consent to participate

Human cancer samples were obtained from patients diagnosed with pancreatic cancer (Asan Medical Center, IRB No. S2013-0744-0009). The biospecimen used in this study was provided by Asan BioResource Center, Korea Biobank Network(2018-21(175)).

Consent for publication

Not applicable

Availability of data and materials

All data generated or analyzed during this study are included in this published article and its supplementary information files.

Competing interests

The authors declare no conflict of interest for this article

\section{Funding}

This study is supported by a grant from the Korean Health Technology R\&D Project, Ministry of Health \& Welfare, Republic of Korea (Grant Number : HI14C2640) and a grant from the Asan Institute for Life Sciences (Grant No. 2017-571). 
Yeon-Sook Choi and Myung Ji Kim performed the main experiments and primary data analyses. Eun A Choi assisted with the in vitro functional study. Eun ji Lee and Hyun Ji Kim provided technical support for the animal and histological studies. Jae Yun Jung contributed to establishing the PDAC-PDX and primary culture. Hyori Kim performed the phage display screening and antibody production. Kyung Kon Kim conducted the proteomic analysis of TIF. Song Cheol Kim provided the tumour specimen under the supervision of the IRB and contributed to the study design and financial support. Suhwan Chang conceived the idea, supervised the research progress, and wrote the manuscript. All the authors have read and approved the final manuscript.

\section{Acknowledgements}

We thank to Dr. Jun Seo Lim (Asan Medical Center) for English editing supports.

\section{References}

1. Chandana S, Babiker HM, Mahadevan D. Therapeutic trends in pancreatic ductal adenocarcinoma (PDAC). Expert Opin Investig Drugs. 2019;28:161-77.

2. Hosein AN, Brekken RA, Maitra A. Pancreatic cancer stroma: an update on therapeutic targeting strategies. Nat Rev Gastroenterol Hepatol. 2020;17:487-505.

3. Wu HZ, Xiao JQ, Xiao SS, Cheng Y. KRAS: A Promising Therapeutic Target for Cancer Treatment. Curr Top Med Chem. 2019;19:2081-97.

4. Waters AM, Der CJ. KRAS: The Critical Driver and Therapeutic Target for Pancreatic Cancer. Cold Spring Harb Perspect Med 2018, 8.

5. Shen W, Tao GQ, Zhang Y, Cai B, Sun J, Tian ZQ. TGF-beta in pancreatic cancer initiation and progression: two sides of the same coin. Cell Biosci. 2017;7:39.

6. Mann KM, Ying H, Juan J, Jenkins NA, Copeland NG. KRAS-related proteins in pancreatic cancer. Pharmacol Ther. 2016;168:29-42.

7. Crawford HC, Pasca di Magliano M, Banerjee S. Signaling Networks That Control Cellular Plasticity in Pancreatic Tumorigenesis, Progression, and Metastasis. Gastroenterology. 2019;156:2073-84.

8. da Cunha BR, Domingos C, Stefanini ACB, Henrique T, Polachini GM, Castelo-Branco P, Tajara EH. Cellular Interactions in the Tumor Microenvironment: The Role of Secretome. J Cancer. 2019;10:4574-87.

9. Haslene-Hox H, Tenstad O, Wiig H. Interstitial fluid-a reflection of the tumor cell microenvironment and secretome. Biochim Biophys Acta. 2013;1834:2336-46.

10. Gromov P, Gromova I, Olsen CJ, Timmermans-Wielenga V, Talman ML, Serizawa RR, Moreira JM. Tumor interstitial fluid - a treasure trove of cancer biomarkers. Biochim Biophys Acta. 2013;1834:2259-70. 
11. Matas-Nadal C, Bech-Serra JJ, Guasch-Valles M, Fernandez-Armenteros JM, Barcelo C, Casanova JM, de la Torre Gomez C, Aguayo Ortiz R, Gari E. Evaluation of Tumor Interstitial Fluid-Extraction Methods for Proteome Analysis: Comparison of Biopsy Elution versus Centrifugation. $J$ Proteome Res 2020.

12. Espinoza JA, Jabeen S, Batra R, Papaleo E, Haakensen V, Timmermans Wielenga V, Moller Talman ML, Brunner N, Borresen-Dale AL, Gromov P, et al. Cytokine profiling of tumor interstitial fluid of the breast and its relationship with lymphocyte infiltration and clinicopathological characteristics. Oncoimmunology. 2016;5:e1248015.

13. Onsurathum S, Haonon O, Pinlaor P, Pairojkul C, Khuntikeo N, Thanan R, Roytrakul S, Pinlaor S. Proteomics detection of S100A6 in tumor tissue interstitial fluid and evaluation of its potential as a biomarker of cholangiocarcinoma. Tumour Biol. 2018;40:1010428318767195.

14. Lee LY, Chen YJ, Lu YC, Liao CT, Chen IH, Chang JT, Huang YC, Chen WH, Huang CC, Tsai CY, Cheng AJ. Fascin is a circulating tumor marker for head and neck cancer as determined by a proteomic analysis of interstitial fluid from the tumor microenvironment. Clin Chem Lab Med. 2015;53:163141.

15. DuFort CC, DelGiorno KE, Hingorani SR. Mounting Pressure in the Microenvironment: Fluids, Solids, and Cells in Pancreatic Ductal Adenocarcinoma. Gastroenterology. 2016;150:1545-57 e1542.

16. Kandimalla R, Tomihara H, Banwait JK, Yamamura K, Singh G, Baba H, Goel A. A 15-Gene Immune, Stromal, and Proliferation Gene Signature that Significantly Associates with Poor Survival in Patients with Pancreatic Ductal Adenocarcinoma. Clin Cancer Res. 2020;26:3641-8.

17. Hauge A, Rofstad EK. Antifibrotic therapy to normalize the tumor microenvironment. J Transl Med. 2020;18:207.

18. Sullivan MR, Danai LV, Lewis CA, Chan SH, Gui DY, Kunchok T, Dennstedt EA, Vander Heiden MG, Muir A: Quantification of microenvironmental metabolites in murine cancers reveals determinants of
tumor nutrient availability. Elife 2019,8 .

19. Jung J, Lee CH, Seol HS, Choi YS, Kim E, Lee EJ, Rhee JK, Singh SR, Jun ES, Han B, et al. Generation and molecular characterization of pancreatic cancer patient-derived xenografts reveals their heterologous nature. Oncotarget. 2016;7:62533-46.

20. Jung J, Jang K, Ju JM, Lee E, Lee JW, Kim HJ, Kim J, Lee SB, Ko BS, Son BH, et al. Novel cancer gene variants and gene fusions of triple-negative breast cancers (TNBCs) reveal their molecular diversity conserved in the patient-derived xenograft (PDX) model. Cancer Lett. 2018;428:127-38.

21. Inohara $\mathrm{H}$, Raz A. Identification of human melanoma cellular and secreted ligands for galectin-3. Biochem Biophys Res Commun. 1994;201:1366-75.

22. Linsley PS, Horn D, Marquardt H, Brown JP, Hellstrom I, Hellstrom KE, Ochs V, Tolentino E. Identification of a novel serum protein secreted by lung carcinoma cells. Biochemistry. 1986;25:2978-86.

23. lacobelli S, Arno E, D'Orazio A, Coletti G. Detection of antigens recognized by a novel monoclonal antibody in tissue and serum from patients with breast cancer. Cancer Res. 1986;46:3005-10. 
24. Stampolidis P, Ullrich A, lacobelli S. LGALS3BP, lectin galactoside-binding soluble 3 binding protein, promotes oncogenic cellular events impeded by antibody intervention. Oncogene. 2015;34:39-52.

25. Zhang $X$, Ding $H$, Lu Z, Ding L, Song Y, Jing Y, Hu Q, Dong Y, Ni Y. Increased LGALS3BP promotes proliferation and migration of oral squamous cell carcinoma via PI3K/AKT pathway. Cell Signal. 2019;63:109359.

26. Lin TW, Chang HT, Chen $\mathrm{CH}$, Chen $\mathrm{CH}$, Lin SW, Hsu TL, Wong CH. Galectin-3 Binding Protein and Galectin-1 Interaction in Breast Cancer Cell Aggregation and Metastasis. J Am Chem Soc. 2015;137:9685-93.

27. Ahn HS, Yeom J, Yu J, Kwon YI, Kim JH, Kim K: Convergence of Plasma Metabolomics and Proteomics Analysis to Discover Signatures of High-Grade Serous Ovarian Cancer. Cancers (Basel) 2020, 12.

28. Andris-Widhopf J, Rader C, Steinberger P, Fuller R, Barbas CF. 3rd: Methods for the generation of chicken monoclonal antibody fragments by phage display. J Immunol Methods. 2000;242:159-81.

29. Lee Y, Kim H, Chung J. An antibody reactive to the Gly63-Lys68 epitope of NT-proBNP exhibits Oglycosylation-independent binding. Exp Mol Med. 2014;46:e114.

30. Salajegheh A, Dolan-Evans E, Sullivan E, Irani S, Rahman MA, Vosgha H, Gopalan V, Smith RA, Lam AK. The expression profiles of the galectin gene family in primary and metastatic papillary thyroid carcinoma with particular emphasis on galectin-1 and galectin-3 expression. Exp Mol Pathol. 2014;96:212-8.

31. Gopalan V, Saremi N, Sullivan E, Kabir S, Lu CT, Salajegheh A, Leung M, Smith RA, Lam AK. The expression profiles of the galectin gene family in colorectal adenocarcinomas. Hum Pathol. 2016;53:105-13.

32. Kobayashi T, Shimura T, Yajima T, Kubo N, Araki K, Tsutsumi S, Suzuki H, Kuwano H, Raz A. Transient gene silencing of galectin-3 suppresses pancreatic cancer cell migration and invasion through degradation of beta-catenin. Int J Cancer. 2011;129:2775-86.

33. Rhim AD, Oberstein PE, Thomas DH, Mirek ET, Palermo CF, Sastra SA, Dekleva EN, Saunders T, Becerra CP, Tattersall IW, et al. Stromal elements act to restrain, rather than support, pancreatic ductal adenocarcinoma. Cancer Cell. 2014;25:735-47.

34. Wu KL, Kuo CM, Huang EY, Pan HM, Huang CC, Chen YF, Hsiao CC, Yang KD. Extracellular galectin-3 facilitates colon cancer cell migration and is related to the epidermal growth factor receptor. Am J Transl Res. 2018;10:2402-12.

35. Kuo HY, Hsu HT, Chen YC, Chang YW, Liu FT, Wu CW. Galectin-3 modulates the EGFR signallingmediated regulation of Sox2 expression via c-Myc in lung cancer. Glycobiology. 2016;26:155-65.

36. Merlin J, Stechly L, de Beauce S, Monte D, Leteurtre E, van Seuningen I, Huet G, Pigny P. Galectin-3 regulates MUC1 and EGFR cellular distribution and EGFR downstream pathways in pancreatic cancer cells. Oncogene. 2011;30:2514-25.

37. Troiani T, Martinelli E, Capasso A, Morgillo F, Orditura M, De Vita F, Ciardiello F. Targeting EGFR in pancreatic cancer treatment. Curr Drug Targets. 2012;13:802-10. 
38. Diersch S, Wirth M, Schneeweis C, Jors S, Geisler F, Siveke JT, Rad R, Schmid RM, Saur D, Rustgi AK, et al. Kras(G12D) induces EGFR-MYC cross signaling in murine primary pancreatic ductal epithelial cells. Oncogene. 2016;35:3880-6.

39. Sodir NM, Kortlever RM, Barthet VJA, Campos T, Pellegrinet L, Kupczak S, Anastasiou P, Swigart LB, Soucek L, Arends MJ, et al. MYC Instructs and Maintains Pancreatic Adenocarcinoma Phenotype. Cancer Discov. 2020;10:588-607.

40. Almagro JC, Pedraza-Escalona M, Arrieta HI, Perez-Tapia SM. Phage Display Libraries for Antibody Therapeutic Discovery and Development. Antibodies (Basel) 2019, 8.

41. Manceau H, Amrani K, Peoc'h K. Personalized medicine, pharmacogenomic and companion biomarker. Ann Biol Clin (Paris). 2017;75:631-6.

42. George TJ Jr, Ogunwobi OO, Sheng W, Fan ZH, Liu C. "Tissue is the issue": circulating tumor cells in pancreatic cancer. J Gastrointest Cancer. 2014;45(Suppl 1):222-5.

43. Jung J, Seol HS, Chang S. The Generation and Application of Patient-Derived Xenograft Model for Cancer Research. Cancer Res Treat. 2018;50:1-10.

44. Garcia PL, Miller AL, Yoon KJ. Patient-Derived Xenograft Models of Pancreatic Cancer: Overview and Comparison with Other Types of Models. Cancers (Basel) 2020, 12.

45. Hsu CW, Chang KP, Huang Y, Liu HP, Hsueh PC, Gu PW, Yen WC, Wu CC. Proteomic Profiling of Paired Interstitial Fluids Reveals Dysregulated Pathways and Salivary NID1 as a Biomarker of Oral Cavity Squamous Cell Carcinoma. Mol Cell Proteomics. 2019;18:1939-49.

46. Dokala A, Thakur SS. Extracellular region of epidermal growth factor receptor: a potential target for anti-EGFR drug discovery. Oncogene. 2017;36:2337-44.

47. Szklarczyk D, Gable AL, Lyon D, Junge A, Wyder S, Huerta-Cepas J, Simonovic M, Doncheva NT, Morris JH, Bork P, et al. STRING v11: protein-protein association networks with increased coverage, supporting functional discovery in genome-wide experimental datasets. Nucleic Acids Res. 2019;47:D607-13.

48. Giansanti F, Capone E, Ponziani S, Piccolo E, Gentile R, Lamolinara A, Di Campli A, Sallese M, lacobelli V, Cimini A, et al. Secreted Gal-3BP is a novel promising target for non-internalizing Antibody-Drug Conjugates. J Control Release. 2019;294:176-84.

49. Piyush T, Chacko AR, Sindrewicz P, Hilkens J, Rhodes JM, Yu LG. Interaction of galectin-3 with MUC1 on cell surface promotes EGFR dimerization and activation in human epithelial cancer cells. Cell Death Differ. 2017;24:1937-47.

50. Blanchard H, Yu X, Collins PM, Bum-Erdene K. Galectin-3 inhibitors: a patent review (2008-present). Expert Opin Ther Pat. 2014;24:1053-65.

51. Yao Y, Zhou L, Liao W, Chen H, Du Z, Shao C, Wang P, Ding K. HH1-1, a novel Galectin-3 inhibitor, exerts anti-pancreatic cancer activity by blocking Galectin-3/EGFR/AKT/FOXO3 signaling pathway. Carbohydr Polym. 2019;204:111-23.

52. Loimaranta V, Hepojoki J, Laaksoaho O, Pulliainen AT. Galectin-3-binding protein: A multitask glycoprotein with innate immunity functions in viral and bacterial infections. J Leukoc Biol. 
2018;104:777-86.

53. Lodermeyer V, Ssebyatika G, Passos V, Ponnurangam A, Malassa A, Ewald E, Sturzel CM, Kirchhoff F, Rotger M, Falk CS, et al: The Antiviral Activity of the Cellular Glycoprotein LGALS3BP/90K Is Species Specific. J Virol 2018, 92.

54. Strobel O, Neoptolemos J, Jager D, Buchler MW. Optimizing the outcomes of pancreatic cancer surgery. Nat Rev Clin Oncol. 2019;16:11-26.

55. Xie X, Zhang X, Chen J, Tang X, Wang M, Zhang L, Guo Z, Shen W. Fe304-solamargine induces apoptosis and inhibits metastasis of pancreatic cancer cells. Int J Oncol. 2019;54:905-15.

56. Guan Y, Reddy KR, Zhu Q, Li Y, Lee K, Weerasinghe P, Prchal J, Semenza GL, Jing N. G-rich oligonucleotides inhibit HIF-1alpha and HIF-2alpha and block tumor growth. Mol Ther. 2010;18:18897.

57. Leal AS, Williams CR, Royce DB, Pioli PA, Sporn MB, Liby KT. Bromodomain inhibitors, JQ1 and I-BET 762, as potential therapies for pancreatic cancer. Cancer Lett. 2017;394:76-87.

58. Gu D, Lin H, Zhang X, Fan Q, Chen S, Shahda S, Liu Y, Sun J, Xie J. Simultaneous Inhibition of MEK and Hh Signaling Reduces Pancreatic Cancer Metastasis. Cancers (Basel) 2018, 10.

59. Edderkaoui M, Chheda C, Soufi B, Zayou F, Hu RW, Ramanujan VK, Pan X, Boros LG, Tajbakhsh J, Madhav A, et al: An Inhibitor of GSK3B and HDACs Kills Pancreatic Cancer Cells and Slows Pancreatic Tumor Growth and Metastasis in Mice. Gastroenterology 2018, 155:1985-1998 e1985.

60. Sharma NS, Gupta VK, Garrido VT, Hadad R, Durden BC, Kesh K, Giri B, Ferrantella A, Dudeja V, Saluja $\mathrm{A}$, Banerjee $\mathrm{S}$. Targeting tumor-intrinsic hexosamine biosynthesis sensitizes pancreatic cancer to anti-PD1 therapy. J Clin Invest. 2020;130:451-65.

61. Johnson BA 3rd, Yarchoan M, Lee V, Laheru DA, Jaffee EM. Strategies for Increasing Pancreatic Tumor Immunogenicity. Clin Cancer Res. 2017;23:1656-69.

\section{Figures}




\section{Figure 1}

A

D

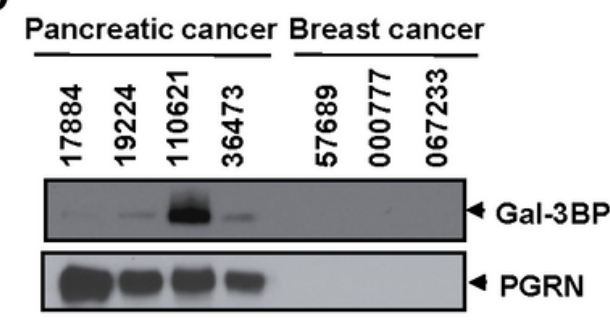

E

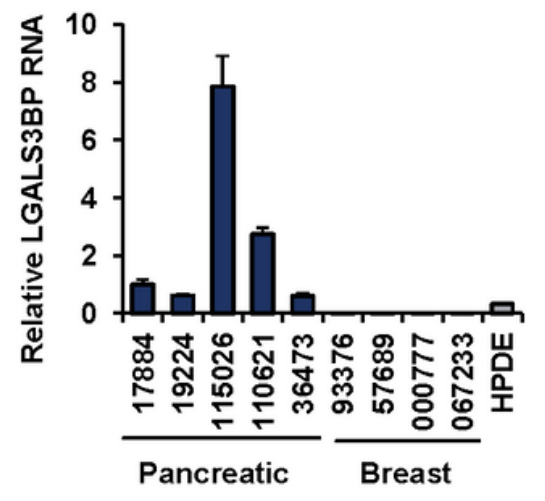

B

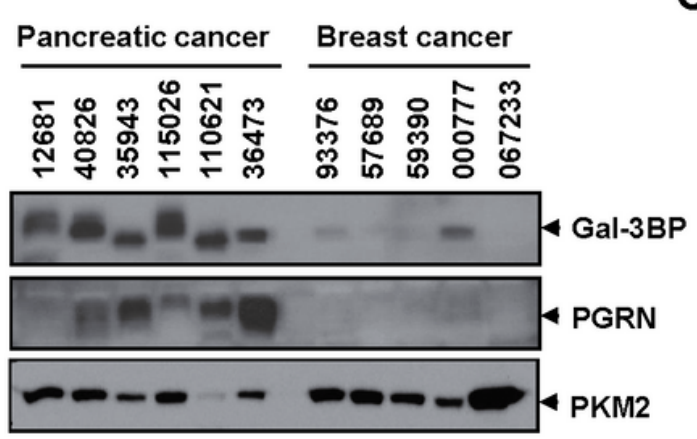

C

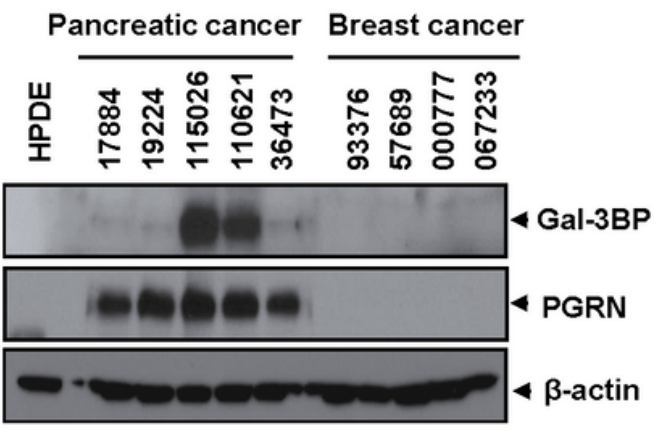

F

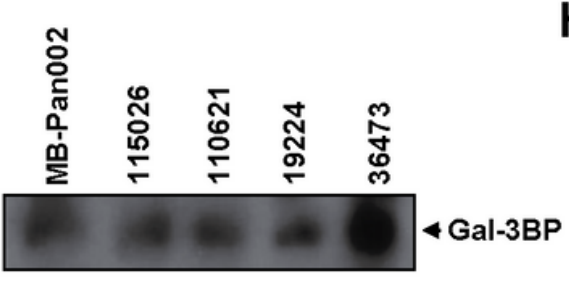

G

H
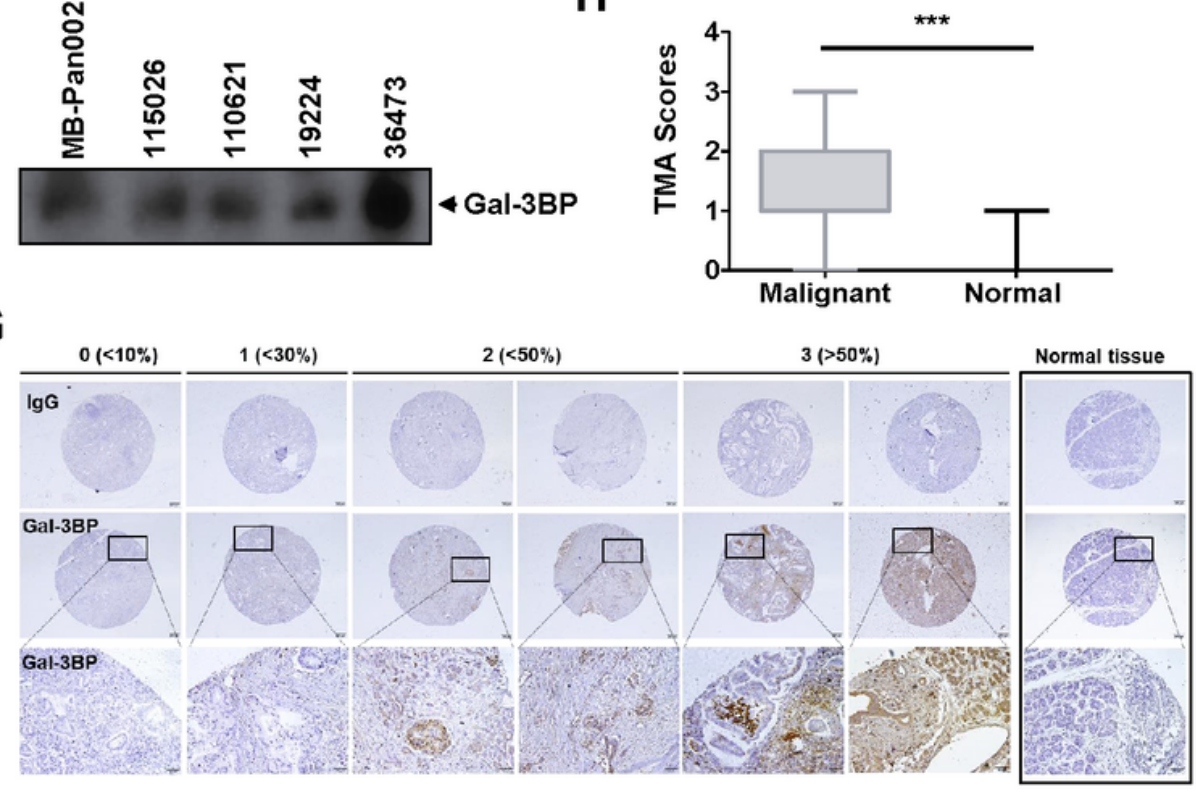

Figure 1

Identification of Gal-3BP, highly secreted in PDAC, by proteomic analysis. (A) Venn diagram depicting the number of proteins quantified via LC-MS/MS analyses. (B-C) Western blot-mediated validation of Gal-3BP and PGRN identified from tumor interstitial fluids (B) and conditioned media from cancer primary cells (C). (D-E) Gal-3BP expression at protein (D) and mRNA (E) level in 5 pancreatic cancer cell primary cells, 4 breast cancer primary cells, and normal pancreatic ductal epithelial cells (HPDE). (F) Detection of Gal-3BP from PDX plasma samples depleted with albumin and IgG. (G) Representative staining images and grading of Tissue Microarray (TMA) comprising PDAC $(n=153)$ and matched normal $(n=21)$. Bottom panels present enlarged part of insets marked in the middle panels. Scale bar; $200 \mu \mathrm{m}$ for top and middle panels, $50 \mu \mathrm{m}$ for bottom panels. $(\mathrm{H})$ A graph showing averaged grade of Gal-3BP staining, obtained from the TMA images ( $n=7$ per group). 
Figure 2

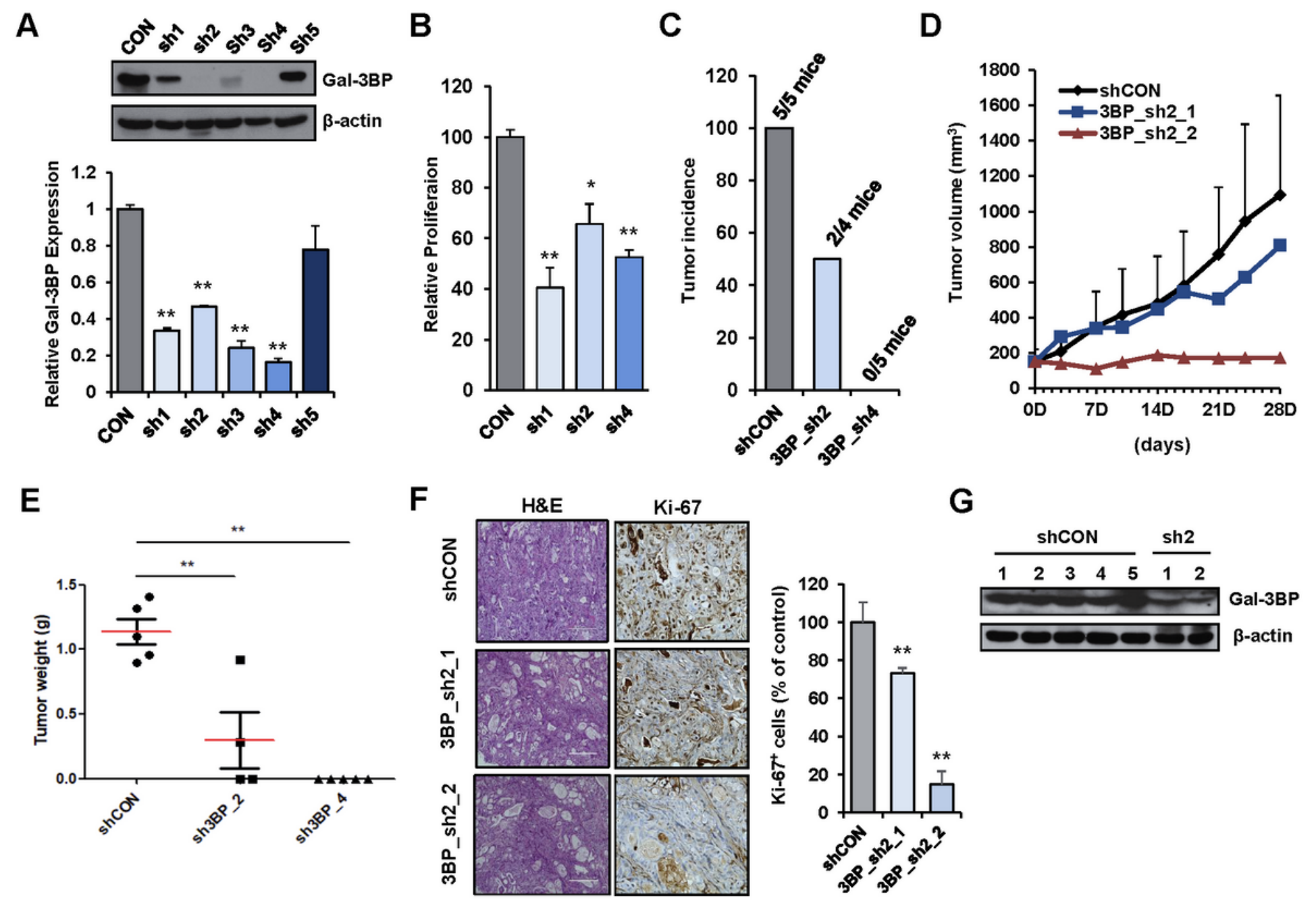

Figure 2

Knockdown of Gal-3BP in PDAC cells attenuates proliferation and tumor formation. (A) Tumor formation upon the subcutaneous injection of 110621 cells transfected with Control shRNA or LGALS3BP shRNA.

(B) Growth curves of 110621 tumors following subcutaneous injection of tumor cells. Black line indicates the average tumor size in mice injected with shRNA control-transfected cells $(n=5)$. The red and blue lines represent the tumor size in each of the two 3BP_sh2 groups. (C) Tumor formation upon subcutaneous injection of 110621 cells transfected with Control shRNA or LGALS3BP shRNA. (D) Growth curves of 110621 tumors following subcutaneous injection of tumor cells. Black line indicates average tumor size in mice injected with shRNA control-transfected cells $(n=5)$. The red and blue lines represent the tumor size in each of the two 3BP_sh2 groups. (E) Ex vivo measurement of tumor weight. (F) Immunohistochemistry depicting Ki67 expression in subcutaneous tumor tissues. Scale bar: $100 \mu \mathrm{m}$. Quantified data were determined based on the number of Ki-67-positive cells. (G) Protein expression analysis of LGALS3BP in tissue lysates from subcutaneous tumor tissue. 
Figure 3

A
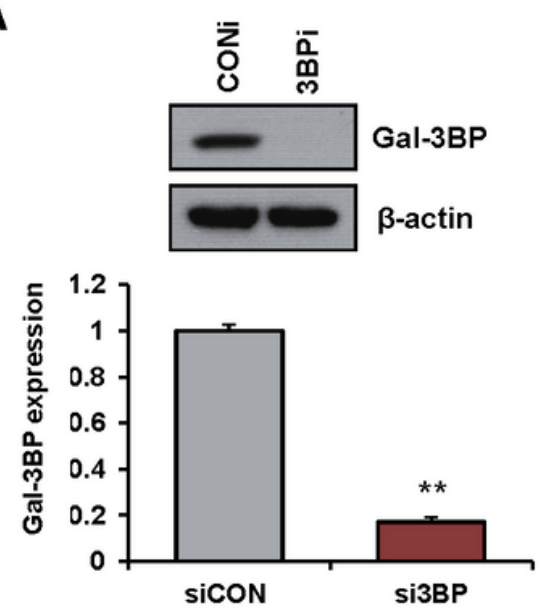

C
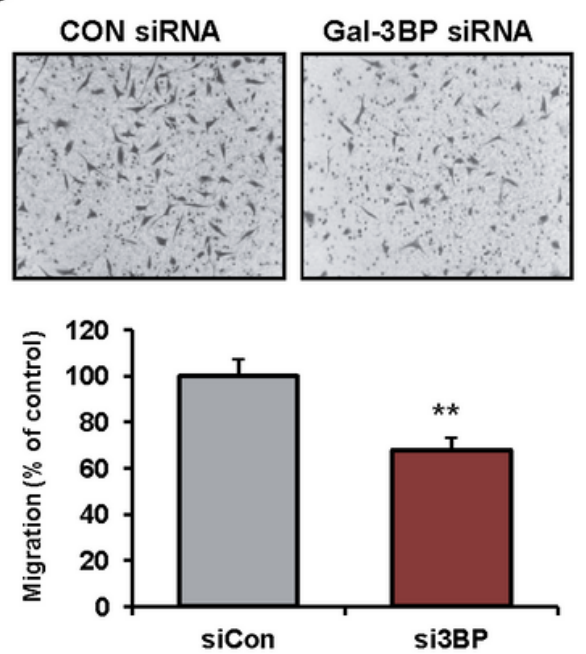

B
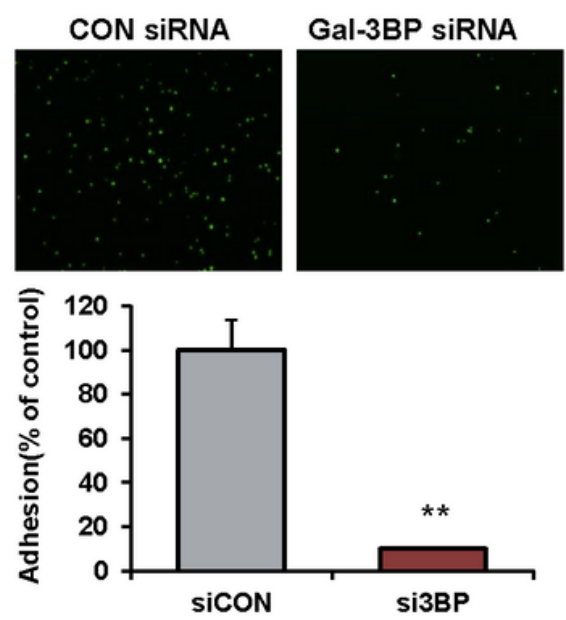

D
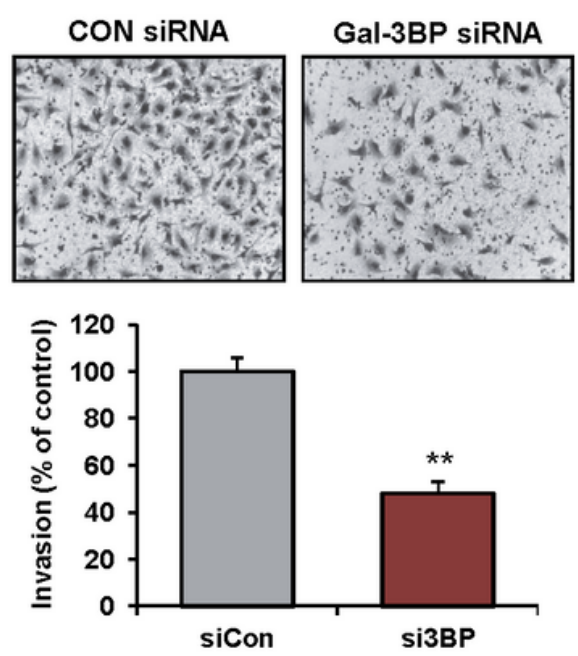

$\mathbf{E}$

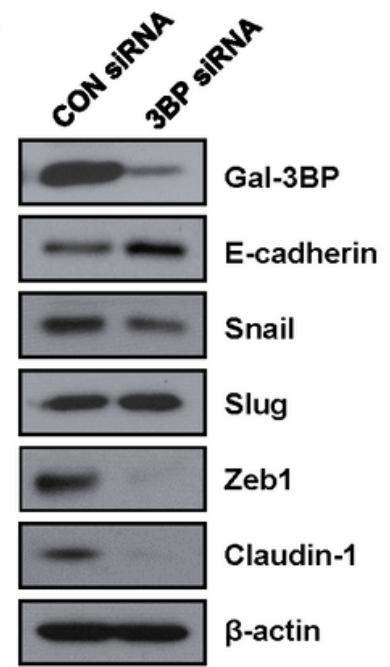

$\mathbf{F}$

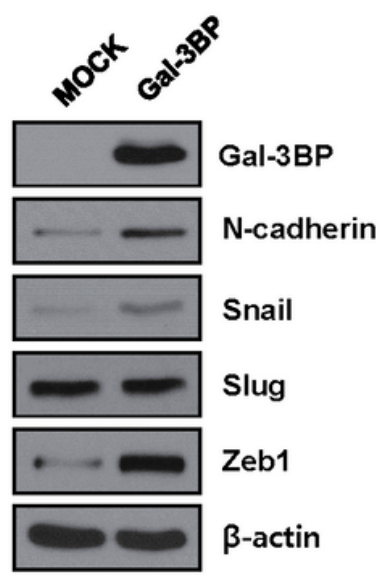

Figure 3

Gal-3BP is required for PDAC cell attachment, migration, and invasion, via the regulation of EMT markers. (A) mRNA and protein levels of LGALS3BP in 110621 pancreatic cancer primary cells after LGALS3BP silencing using siRNA, determined by real-time PCR and western blotting. (B) Adhesion assay of 110621 cells transfected with LGALS3BP siRNA (si3BP) or negative control (siCON). Representative images are shown. Bar graph indicates the adherent cell count. (C-D) Migration (C) and Matrigel-coated transwell invasion assay for110621 pancreatic cancer cells transfected with LGALS3BP siRNA (si3BP) or control siRNA (siCON). Representative microscopic images of cells on membrane, from each group. (E) Western blot analysis of EMT markers in control and LGALS3BP knockdown cells (110621). (F) Western blot analysis of EMT markers in cells with LGALS3BP overexpression (17884). 
Figure 4

A

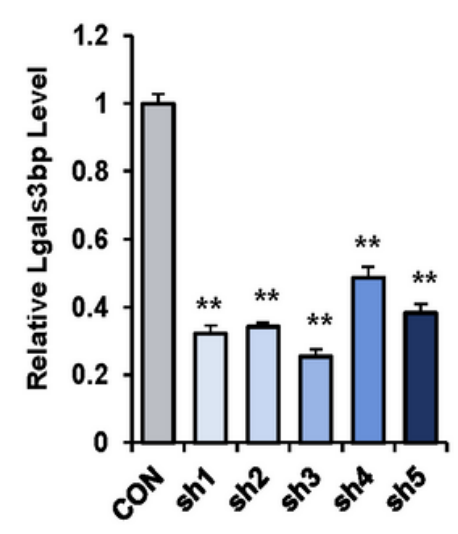

B

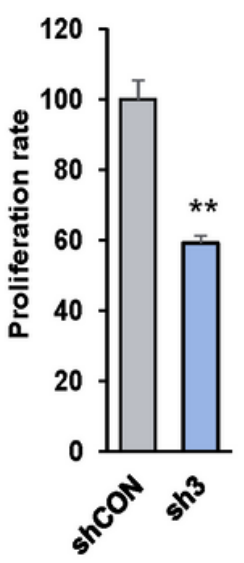

C

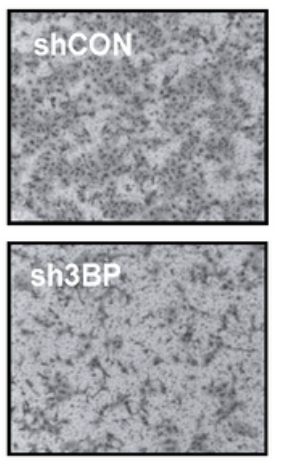

F

E

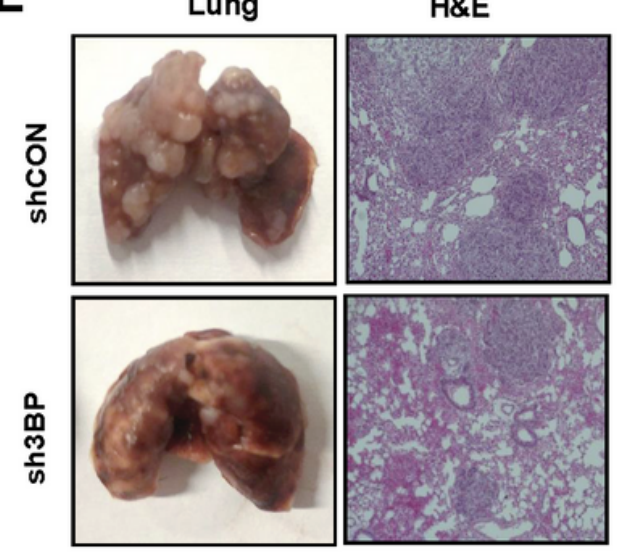

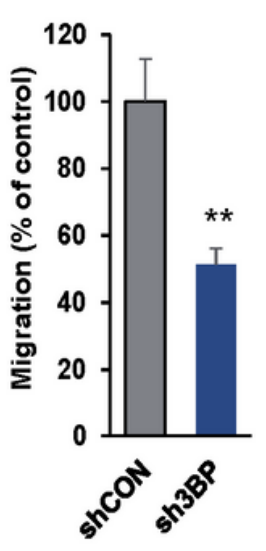

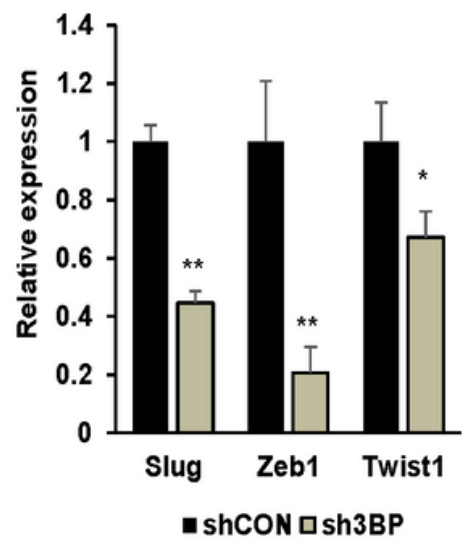

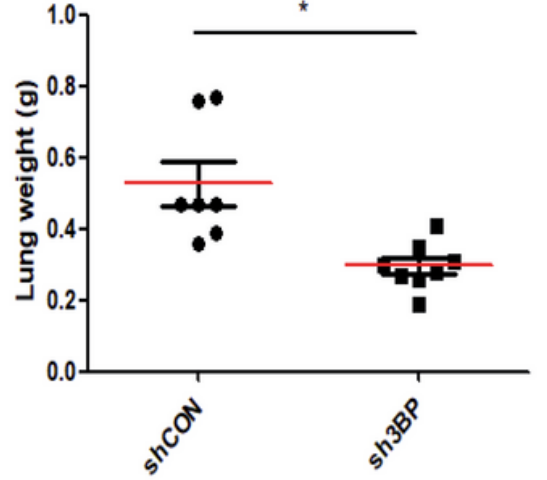

G

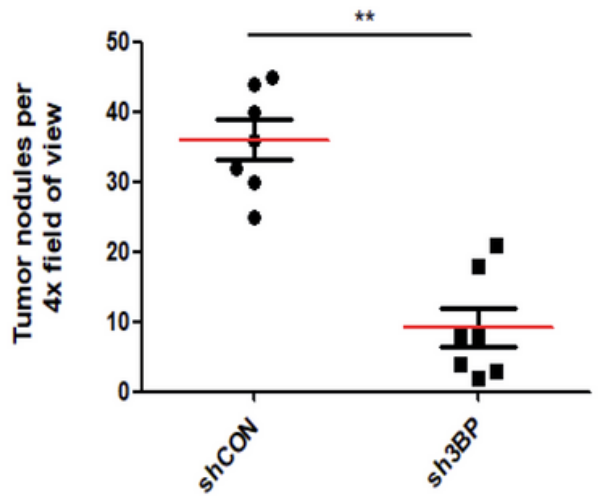

Figure 4

Stable knockdown of Gal-3BP suppresses PDAC metastasis in mouse allograft model. (A) Relative level of Lgals3bp RNA in mouse PDAC cells upon shRNA mediated knockdown. (B-D) Reduced proliferation rate (B), migration (C), and EMT marker expression (D) in mouse PDAC cells after the knockdown of Gal3BP. (E) Representative images of lung metastasis (left) and H\&E staining of lung sections (right) from mice injected with control (shCON) or Lgals3bp knockdown (sh3BP) cells. Scale bar : $400 \mu \mathrm{m}(\mathrm{F}-\mathrm{G})$ Graphs depicting lung weight $(F)$ and the number of metastatic lung nodules $(G)$. 
Figure 5

A

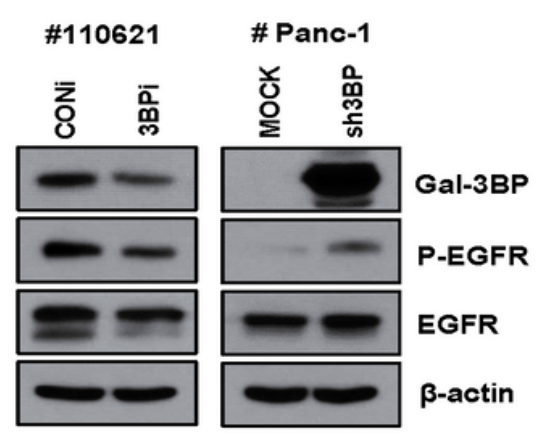

D
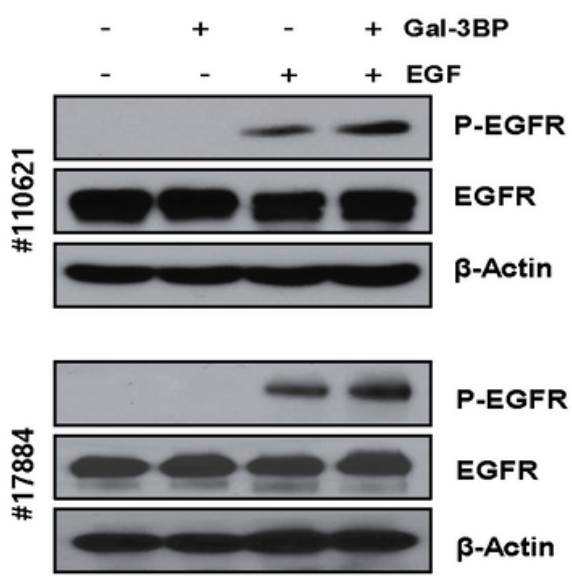

B

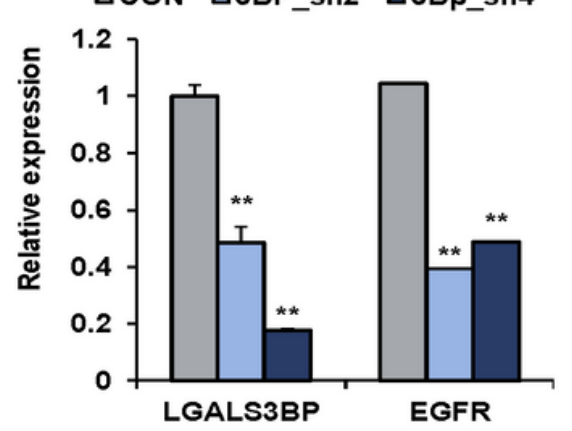

E

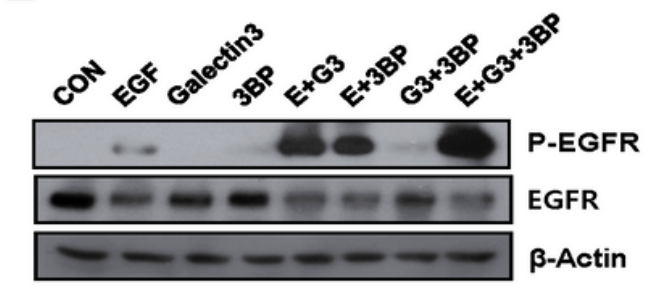

F

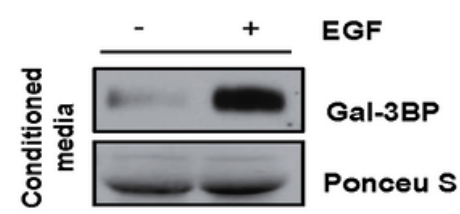

C

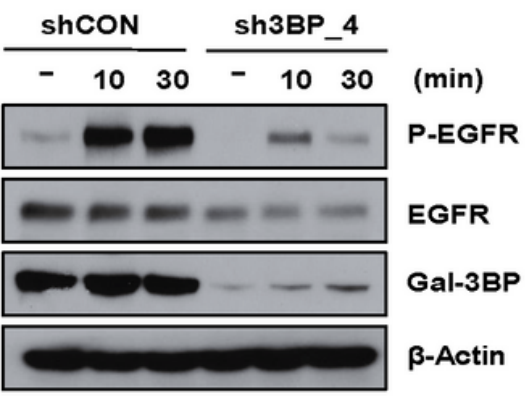

G

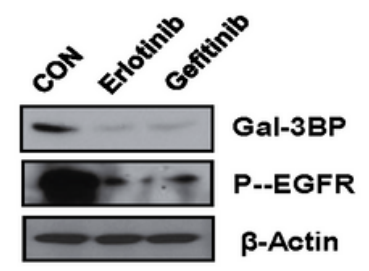

H

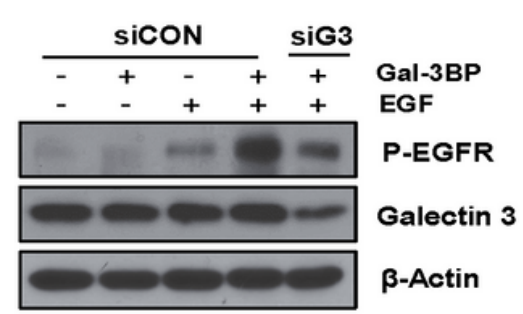

Figure 5

Gal3-BP enhances EGFR signalling in human PDAC cells. (A) Gal3-BP knockdown attenuates EGFR activation. Western blotting to check for EGFR, p-EGFR, and Gal-3BP levels after siRNA-mediated knockdown of Gal-3BP in 110621 cells (left) or overexpression in Panc-1 cells (right). (B) Expression analysis of Gal3-BP and EGFR mRNA levels in two independent 110621 clonal cells (sh2 and sh4) with the stable knockdown of Gal-3BP. (C) Decreased phosphorylation and expression of EGFR in the background of Gal3BP knockdown and treatment with $50 \mathrm{ng} / \mathrm{ml}$ of EGF for the indicated time periods. (D) Gal-3BP enhances EGFR activation. Phosphorylation of EGFR was determined by western blotting in 110621 (Gal3BP expression high cells) and 17884 (Gal-3BP expression low cells), after the combinatory treatment of Gal-3BP $(250 \mathrm{ng} / \mathrm{ml})$ and EGF $(50 \mathrm{ng} / \mathrm{ml})$. (E) Both Galectin-3 and Gal-3BP enhance EGFR activation. Phosphorylation of EGFR was determined by western blotting, after combinatorial treatment with Gal-3BP (250 ng/ml), Galectin-3 (100 ng/ml), and EGF (50 ng/ml). (F) EGF stimulates Gal-3BP secretion.

Expression analysis of secreted Gal-3BP in conditioned media by western blotting, after treatment with EGF. (G) Inhibition of EGFR suppresses Gal-3BP expression. 110621 cells were treated with Erlotinib and Gefitinib for 2 days and then subjected to western blotting for checking the levels of Gal-3BP and p-EGFR. (H) Galectin-3 contributes to Gal-3BP-driven EGFR activation. Phosphoactivation of EGFR was determined after combinatorial treatment with Gal3-BP, EGF, and Gal3-BP siRNA. 
Figure 6

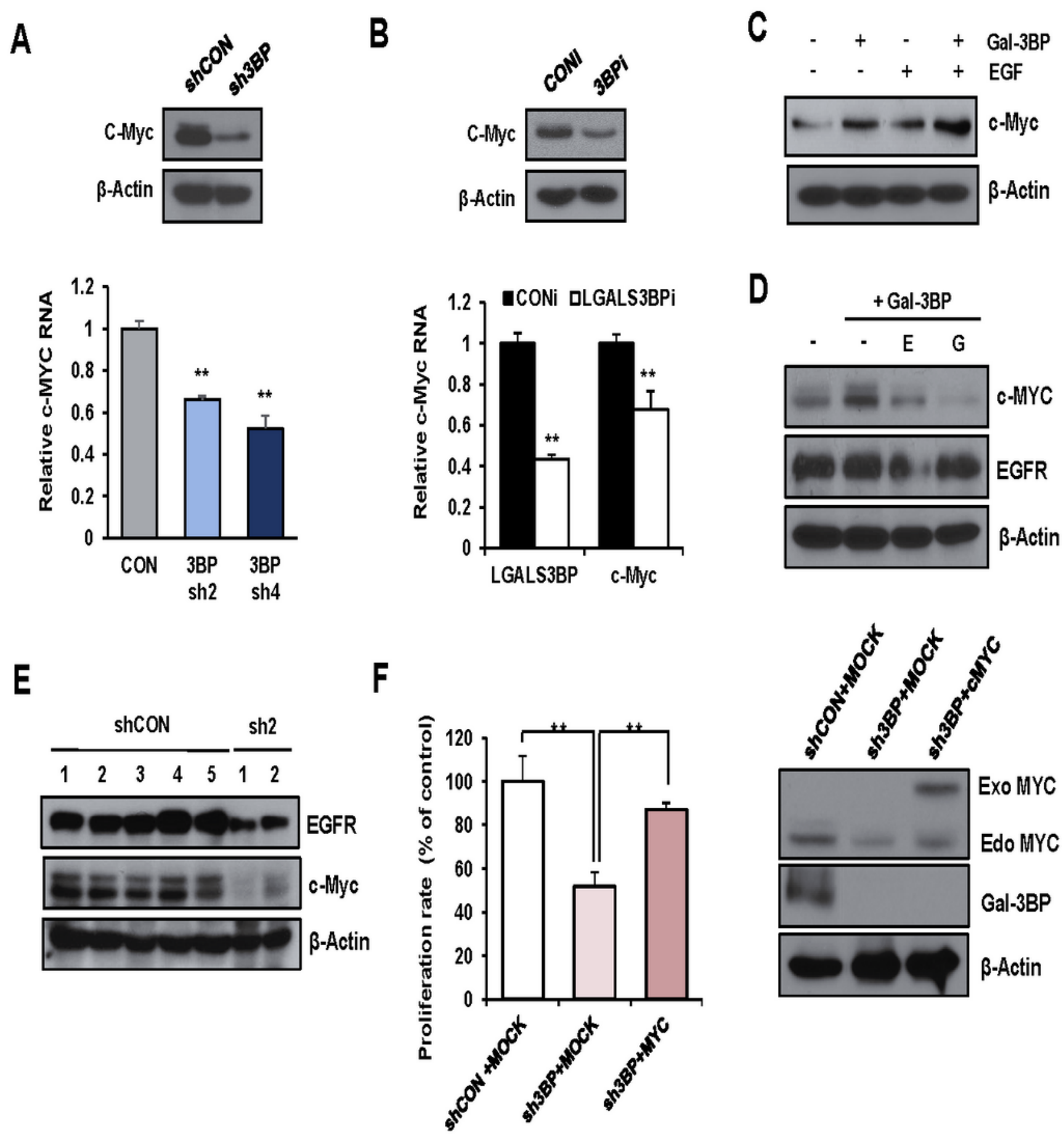

Figure 6

cMyc mediates Gal-3BP-driven EGFR activation signal. (A) Reduced cMyc protein (top) or RNA (bottom) expression after knocking down Gal-3BP using shRNA (sh3BP). Reduced levels of cMyc mRNA were detected in two 3BP-shRNA clonal cells (sh2 and sh4). (B) Transient Gal-3BP knockdown attenuates cMyc expression in primary PDAC cells. Top panel shows cMyc protein and bottom panel shows RNA levels of Gal-3BP and cMyc. (C) Exogenous Gal3-BP increases cMyc expression in primary PDAC cells. 
Cells were treated with Gal-3BP $(250 \mathrm{ng} / \mathrm{ml})$ and/or EGF $(50 \mathrm{ng} / \mathrm{ml})$ for $48 \mathrm{~h}$ and the expression of cMyc was examined. (D) EGFR inhibitor suppresses Gal-3BP driven cMyc expression. Primary PDAC cells were pre-treated with Erlotinib or Gefitinib prior to the addition of Gal-3BP. cMyc protein was detected by western blotting. (E) Depletion of Gal3-BP in tumor suppresses cMyc expression. Western blot analysis of EGFR and cMyc was performed in tumor lysates obtained from the mouse model shown in Fig. $2 \mathrm{C}$ and 2D. (F) cMyc restores PDAC proliferation attenuated upon Gal-3BP knockdown. Primary PDAC cells with Gal-3BP knockdown were transfected with empty vector (MOCK) or cMyc overexpression plasmid and proliferation was measured. The level of cMyc protein was confirmed by western blot (right panel).

Figure 7

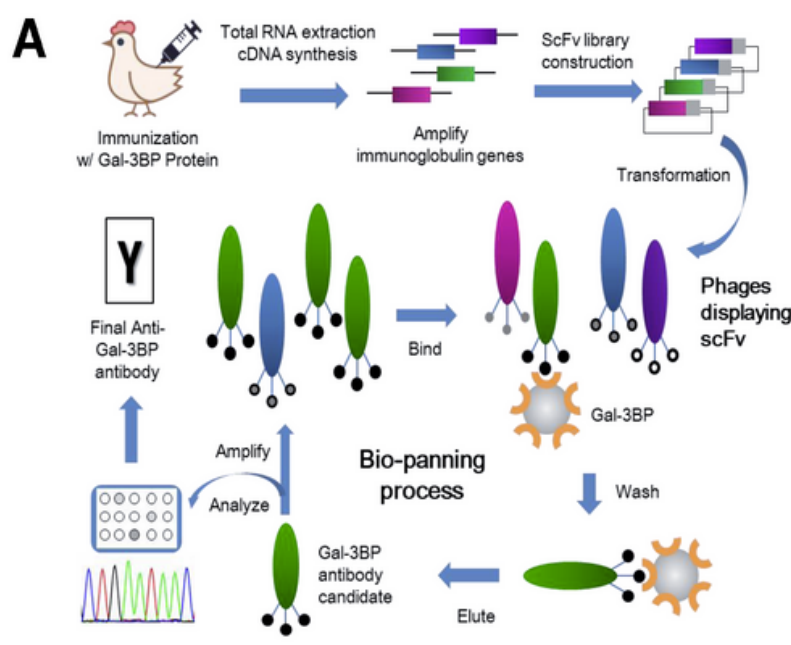

E

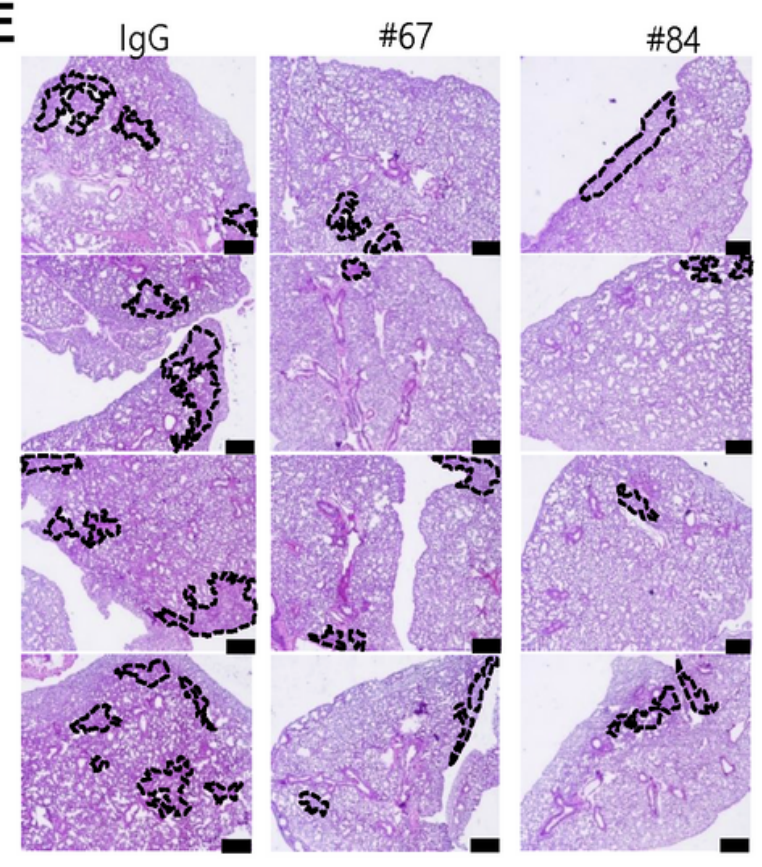

B

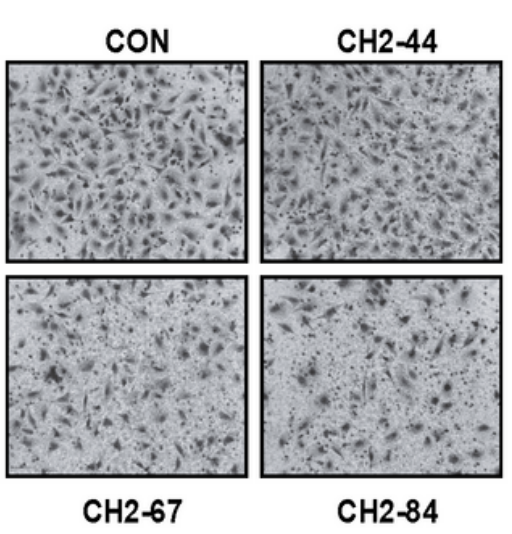

D

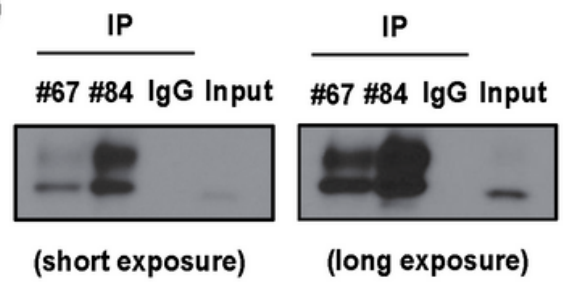

$F$

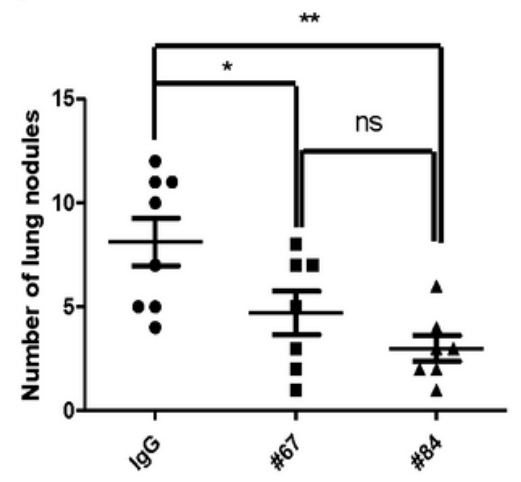

C

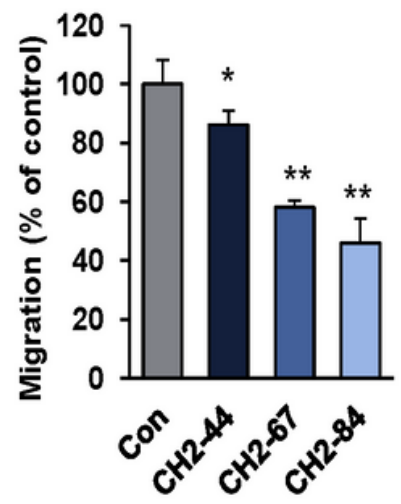

Gal-3BP

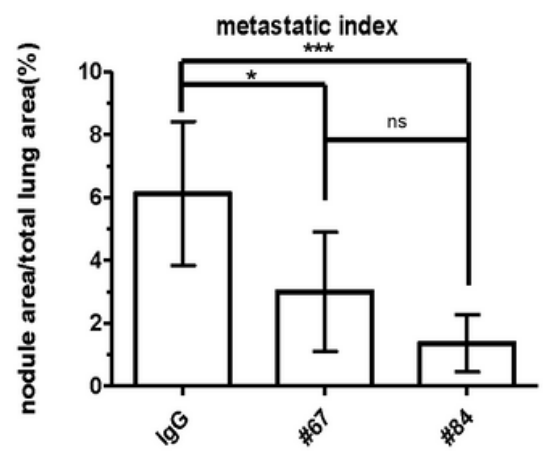

Figure 7

Anti-Gal-3BP antibody isolated by phage display attenuates the migration of PDAC cells and metastasis in a patient-derived preclinical model. (A) Schematic diagram depicting the Gal3-3BP antibody screening by phage display technique. (B- C) Inhibitory effect of Gal3-3BP antibody ( $\mathrm{CH} 2-44, \mathrm{CH} 2-67, \mathrm{CH} 2-84)$ on 
pancreatic cancer cells (110621) migration. Representative image of migration (B) and its quantitation (C) are shown. (D) Immunoprecipitation followed by western blot demonstrated that two antibody clones (\#67 and \#84) binds with Gal3-BP. Cells treated with IgG were used as a negative control. (E) Representative H\&E staining of lung sections obtained from mice injected with primary PDAC cells. Metastasized tumor regions are demarcated by black-dotted grids; scale bar $=200 \mathrm{IM}$. (F) A graph showing the nodule count from three groups ( $\mathrm{IgG}, \# 67$, and \#84; $n=22)$. (G) A graph showing metastatic index, indicating the area occupied by tumor cells in each lung $(n=22)$.

\section{Supplementary Files}

This is a list of supplementary files associated with this preprint. Click to download.

- GraphicalAbs.jpg

- JECCR3BPsupplementaryinfo.pdf 